\title{
Electrochemical Evaluation of Linseed Oil as Environment- friendly Inhibitor for Corrosion of Steel in HCI Solution
}

\author{
L. Afia, ${ }^{a}$ R. Salghi, ${ }^{a, *}$ O. Benali, ${ }^{b}$ S. Jodeh, ${ }^{c, *}$ I. Warad, ${ }^{c}$ \\ E. Ebenso ${ }^{d}$ and B. Hammouti \\ ${ }^{a}$ Laboratory of Environmental Engineering and Biotechnology, ENSA, Ibn Zohr University, \\ P.O. Box 1136, 80000 Agadir, Morocco \\ ${ }^{b}$ Department of Biology, Faculty of Sciences, Dr. Tahar Moulay University of Saïda, Algeria \\ ${ }^{c}$ Department of Chemistry, An-Najah National University, P. O. Box 7, Nablus, Palestine \\ ${ }^{d}$ Material Science Innovation \& Modelling (MaSIM) Research Focus Area, Faculty of \\ Agriculture, Science and Technology, North-West University (Mafikeng Campus), \\ Private Bag X2046, Mmabatho 2735, South Africa \\ ${ }^{e}$ LCAE-URAC 18, Faculty of Science, University of Mohammed Premier, \\ P.O. Box 71760000 Oujda, Morocco
}

Received 28 May 2015; accepted 25 June 2015

\begin{abstract}
The effect of linseed oil (LO) on the corrosion of carbon steel in $1 \mathrm{M} \mathrm{HCl}$ solution was investigated using potentiodynamic polarization, electrochemical impedance spectroscopy (EIS) technique and weight loss measurements. The inhibiting action increases with the concentration of the tested inhibitor. The highest efficiency $(98.2 \%)$ is obtained at $3 \mathrm{~g} / \mathrm{L}$ of $\mathrm{LO}$. The influence of temperature on the corrosion behavior of carbon steel in $1 \mathrm{M} \mathrm{HCl}$, with the addition of $\mathrm{LO}$ was also studied. The obtained data from EIS measurements were analyzed to model the corrosion inhibition process through an appropriate equivalent circuit model; a constant phase element (CPE) has been used. Polarization measurements show also that LO acts as a good mixed inhibitor. The inhibition process is attributed to the formation of an adsorbed film of the inhibitor on the metal surface which protects the metal against corrosion. LO is adsorbed on the steel surface according to a Langmuir isotherm adsorption model. The results obtained showed that the linseed oil could serve as an effective green inhibitor of the corrosion of carbon steel in hydrochloric acid medium.
\end{abstract}

Keywords: corrosion, carbon steel, inhibition, linseed oil.

\footnotetext{
"Corresponding author. E-mail address: r.salghi@uiz.ac.ma, sjodeh@najah.edu
} 


\section{Introduction}

The study of corrosion inhibition of steel using a green inhibitor in acidic media containing $\mathrm{HCl}$ or $\mathrm{H}_{2} \mathrm{SO}_{4}$ in particular, is one of the challenging topics of the current research in various industries involving chemical cleaning, descaling, pickling, acid oil-well acidizing, etc. [1-5]. Due to the aggressiveness of these acids a substantial economic loss is suffered by the concerned industries resulting from rapid corrosion of metallic parts. Inhibitors are generally used in these processes to control metal dissolution as well as the consumption of acid $[6,7]$. However, most of the conventional inhibitors that were developed to combat this endemic problem are highly toxic to human beings and have the potential to degrade the environment. Recent studies on green inhibitors have shown that they are more effective and highly environmentally benign compared to organic and inorganic inhibitors used in chemical and petrochemical industries. Among the natural products, plant extracts find a prominent place. The abundant phytochemical constituents of plant extracts possess considerable potential as inexpensive, non toxic and renewable sources of a wide range of organic chemicals of industrial significance. Moreover, they are also biodegradable in nature. The use of these natural products such as extracted compounds from leaves or seeds as corrosion inhibitors has been widely reported by a number of publications such as: Argan oils and extracts [8-13], Schinopsis lorentzii [14], Oxandra asbecki [15], Argemone mexicana [16], Neolamarckia cadamba [17], Justicia gendarussa [18], Aloe vera [19], Marigold flower [20], Bambusa Arundinacea leaves [21], antibacterial drugs [22], Jasminum nudiflorum Lindl. leaves [23], vanillin [24], Gum Arabic [25], polysaccharid [26], adhatoda vasica [27], rotula aquatica lour. [28], petersianthus macrocarpus [29], Chamaerops humilis [30].

This study represents helpful efforts to investigate a new biodegradable compound derived from linseed seeds as inhibitor for corrosion of steel in $1 \mathrm{M}$ $\mathrm{HCl}$ solution, by weight loss, potentiodynamic polarization, and electrochemical impedance spectroscopy (EIS) methods.

\section{Experimental methods}

\section{Plant collection and essential oil extraction}

The oil subjected to study was the organic virgin linseed oil obtained by cold pressing of linseed seeds, acquired in a local supermarket in Agadir/Morocco. Linseed seeds are cleaned, dried in umbra and cold pressing by hydraulic press without any use of chemicals or solvents. Once this pressure is made, the linseed oil is then filtered and stored absolutely safe from light and heat to prevent rancidity.

\section{Solutions preparation}

The $1 \mathrm{M} \mathrm{HCl}$ solution was prepared by dilution of analytical-grade $37 \% \mathrm{HCl}$ with double-distilled water. Test solutions were freshly prepared before each experiment, by adding the oil directly to the corrosive solution. Experiments were conducted in triplicate to enable determination of reproducibility. 


\section{Fatty acid methyl esters composition}

The analysis performed for the purpose of this study were carried out in the laboratory of the Autonomous Establishment of Control and Coordination of Export which applies the official methods of analysis for the determination of fatty acid methyl esters (FAME) in oil [31-33]. The fatty acid methyl esters were analyzed with an Agilent Technologies $6890 \mathrm{~N}$ gas chromatograph equipped with a capillary column (30 m x $0.32 \mathrm{~mm}$; Supelco, Bellefonte, PA, USA) and flame ionization detection. The column was programmed to increase from 135 to 160 ${ }^{\circ} \mathrm{C}$ at $2{ }^{\circ} \mathrm{C} / \mathrm{min}$ and from 160 to $205^{\circ} \mathrm{C}$ at $1.5^{\circ} \mathrm{C} / \mathrm{min}$; the detection temperature was maintained at $220{ }^{\circ} \mathrm{C}$, injector temperature $220{ }^{\circ} \mathrm{C}$. The vector gas was helium at a pressure of $5520 \mathrm{~Pa}$. Peaks were identified by comparing retention times with those of standard fatty acid methyl esters.

\section{Weight loss measurements}

Coupons cut into $2 \times 2 \times 0.08 \mathrm{~cm}^{3}$ dimensions having composition $(0.179 \% \mathrm{C}$, $0.165 \% \mathrm{Si}, 0.439 \% \mathrm{Mn}, 0.203 \% \mathrm{Cu}, 0.034 \% \mathrm{~S}$ and $\mathrm{Fe}$ balance) are used for weight loss measurements. Prior to all measurements, the exposed area was mechanically abraded with 180, 320, 800 grades of emery papers. The specimens are washed thoroughly with bidistilled water, degreased and dried with ethanol. Gravimetric measurements are carried out in a double walled glass cell equipped with a thermostated cooling condenser. The solution volume is $80 \mathrm{~cm}^{3}$. The immersion time for the weight loss is $8 \mathrm{~h}$ at $298 \mathrm{~K}$.

\section{Electrochemical tests}

The electrochemical study was carried out using a potentiostat PGZ100 piloted by Voltamaster software. This potentiostat is connected to a cell with three electrode thermostats with double wall (Tacussel Standard CEC/TH). A saturated calomel electrode (SCE) and a platinum electrode were used as reference and auxiliary electrodes, respectively. The material used for constructing the working electrode was the same used for gravimetric measurements. The surface area exposed to the electrolyte is $0.56 \mathrm{~cm}^{2}$. Potentiodynamic polarization curves were plotted at a polarization scan rate of $0.5 \mathrm{mV} / \mathrm{s}$. Before all experiments, the potential was stabilized at free potential during $30 \mathrm{~min}$. The polarisation curves are obtained from $-700 \mathrm{mV}$ to $-300 \mathrm{mV}$ at $298 \mathrm{~K}$. The solution test is thereafter de-aerated by bubbling nitrogen. Gas bubbling is maintained prior and through the experiments. In order to investigate the effects of temperature and immersion time on the inhibitor performance, some tests were carried out in the temperature range 298-328 K. The electrochemical impedance spectroscopy (EIS) measurements are carried out with the electrochemical system (Tacussel), which included a digital potentiostat model Voltalab PGZ100 computer at $\mathrm{E}_{\text {corr }}$ after immersion in solution without bubbling. After the determination of the steady-state current at a corrosion potential, sine wave voltage $(10 \mathrm{mV})$ peak to peak, at frequencies between $100 \mathrm{kHz}$ and $10 \mathrm{mHz}$ are superimposed on the rest potential. Computer programs automatically controlled the measurements performed at rest potentials after $30 \mathrm{~min}$ of 
exposure at $298 \mathrm{~K}$. The impedance diagrams are given in the Nyquist representation. Experiments are repeated three times to ensure the reproducibility.

\section{Results and discussion}

\section{Linseed oil analysis}

The analysis of linseed oil allowed the identification of 12 components which accounted for fatty acid methyl esters (Table 1). As seen in Table 1, the main constituents were linolenic acid (52.9\%), oleic acid (19.7\%) and linoleic acid $(14.8 \%)$. As a result linseed oil is a triglyceride (Fig. 1), like other fats, and distinctive oil for its unusually large amount of $\alpha$-linolenic acid, which has a distinctive reaction with oxygen in air.

Table 1. Chemical composition of linseed oil.

\begin{tabular}{l|c}
\hline Fatty acid methyl esters & \% \\
\hline Myristic acid (C14 :0) & 0.3 \\
\hline Pentadecanoic acid (C15:0) & 0.1 \\
\hline Palmitic acid (C16:0) & 5.6 \\
\hline Palmitoleic acid (C16:1) & 1.4 \\
\hline Heptadecanoic acid (C17:0) & 0.2 \\
\hline Stearic acid (C18:0) & 4.5 \\
\hline Oleic acid (C18:1) & 19.7 \\
\hline Linoleic acid (C18:2) & 14.8 \\
\hline Linolenic acid (C18:3) & 52.9 \\
\hline Arachidic acid (C20:0) & 0.2 \\
\hline Gadoleic acid (C20:1) & 0.3 \\
\hline
\end{tabular}

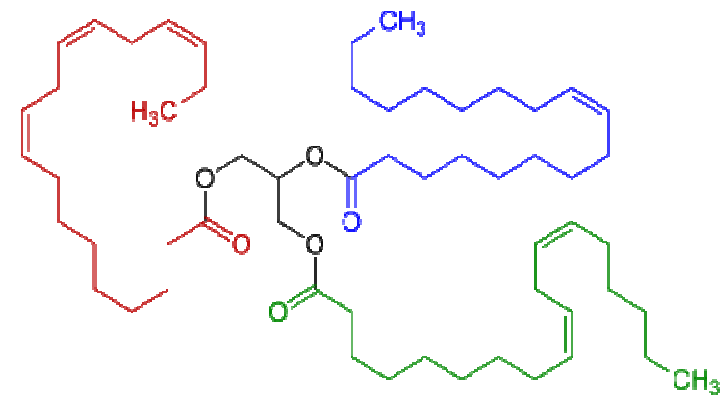

Figure 1. Representative triglyceride found in a linseed oil, a triester (triglyceride) derived of linoleic acid, alpha-linolenic acid, and oleic acid.

\section{Effect of concentration}

Polarization curves

Potentiodynamic polarisation curves of carbon steel in $1 \mathrm{M} \mathrm{HCl}$ in the absence and presence of LO at different concentrations at $298 \mathrm{~K}$ are presented in Fig. 2. The corrosion parameters including corrosion current densities $\left(\mathrm{I}_{\text {corr }}\right)$, corrosion potential $\left(\mathrm{E}_{\mathrm{corr}}\right)$, cathodic Tafel slope $\left(\mathrm{b}_{\mathrm{c}}\right)$, anodic Tafel slop $\left(\mathrm{b}_{\mathrm{a}}\right)$ and inhibition efficiency $\left(\mathrm{E}_{\mathrm{I}} \%\right)$ are listed in Table 2. 


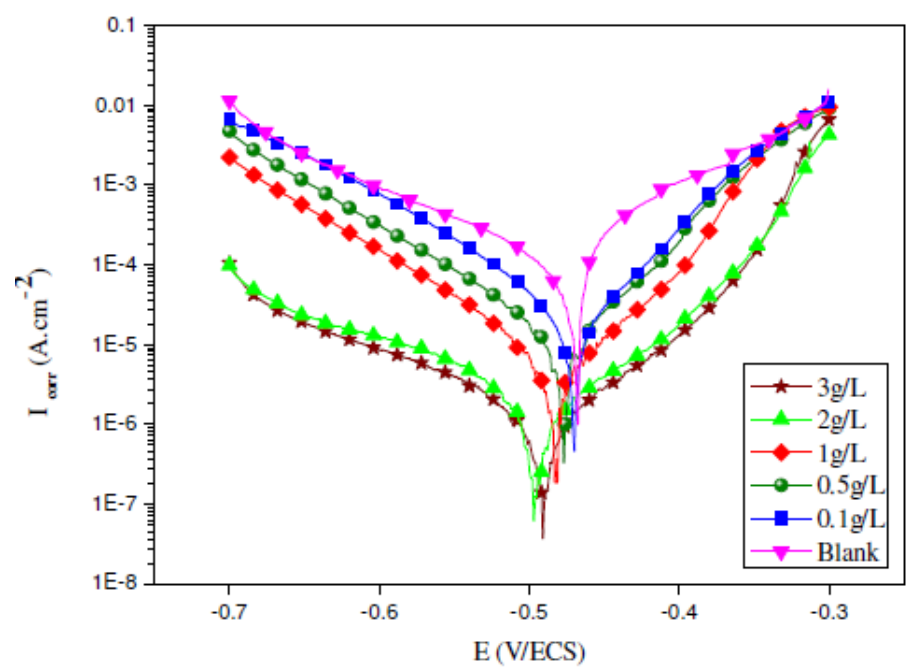

Figure 2. Potentiodynamic polarization curves for carbon steel in $1 \mathrm{M} \mathrm{HCl}$ in the absence and presence of LO at $298 \mathrm{~K}$.

Table 2. Electrochemical parameters of carbon steel at various concentrations of LO in $1 \mathrm{M} \mathrm{HCl}$ and corresponding inhibition efficiency.

\begin{tabular}{lllll}
\hline Conc. $(\mathbf{g} / \mathbf{L})$ & $\mathbf{E}_{\text {corr }}(\mathbf{m V} / \mathbf{S C E})$ & $\mathbf{I}_{\text {corr }}\left(\boldsymbol{\mu} \mathbf{A} / \mathbf{c m}^{2}\right)$ & $\mathbf{- b}_{\mathbf{c}}(\mathbf{m V} / \mathbf{d e c})$ & $\mathbf{E}_{\mathbf{I}}(\boldsymbol{\%})$ \\
\hline Blank & -467 & 96.0 & 99 & -- \\
0.1 & -471 & 42.9 & 94 & 55.4 \\
0.5 & -477 & 23.8 & 91 & 75.3 \\
1 & -482 & 13.2 & 88 & 86.2 \\
2 & -496 & 5.4 & 90 & 94.4 \\
3 & -490 & 1.7 & 88 & 98.2 \\
\hline
\end{tabular}

In this case, the inhibition efficiency is defined as follows:

$$
\mathrm{E} \%=\left(1-\frac{\mathrm{I}_{\text {corr }}}{\mathrm{I}_{\text {corr }}}\right) \times 100
$$

where $\mathrm{I}_{\text {corr }}$ and $\mathrm{I}_{\text {corr }}$ are current density in absence and presence of LO, respectively.

We noted that $\mathrm{I}_{\text {corr }}$ and I' corr were calculated from the intersection of cathodic and anodic Tafel lines. The visual examination of polarization curves depicted in Fig. 2 , reveals that the corrosion current density decreased as the concentration of inhibitor increased. Addition of LO to acid media affected both cathodic and anodic branches of the potentiodynamic polarization curves. However, corrosion potential shifted to negative direction more markedly. Generally, if the displacement in $\mathrm{E}_{\text {corr }}$ is higher than $85 \mathrm{mV}$ with respect to $\mathrm{E}_{\text {corr }}$ in uninhibited solution, the inhibitor can be seen as of a cathodic or anodic type [40-41]. In our study the maximum displacement is $29 \mathrm{mV}$, which indicates that $\mathrm{LO}$ acts as a mixed-type inhibitor at $298 \mathrm{~K}$. This shows that the effect of the inhibitor on the cathodic reaction is more observable than on the anodic reaction.

As it can be seen from Table 2, inhibition efficiency values increased from $55.4 \%$ to $98.2 \%$ with the increment of LO concentration. An increase in inhibitor concentration up to $3 \mathrm{~g} / \mathrm{L}$ didn't increase the $\mathrm{E}_{\mathrm{I}}$. These results also show that $\mathrm{LO}$ acts as an effective inhibitor. It is noted that, the modes of the inhibition effect are classified into three categories [34, 36-41]: geometric blocking effect of 
adsorbed inhibitive species, active sites blocking effect by adsorbed inhibitive species, and electrocatalytic effect of the inhibitor or its reaction products. It has been discussed in the case of the first mode that inhibition effect comes from the reduction of the reaction area on the surface of the corroding metal, whereas for the other two modes the inhibition effects are due to the changes in the average activation energy barriers of the anodic and cathodic reactions of the corrosion process. The cathodic Tafel constant values $\left(b_{c}\right)$ did not change significantly, which suggests that the inhibition is most probably caused by a geometric blocking effect of the adsorbed inhibitive species on the surface corroding metal. The parallel cathodic Tafel lines (Fig. 2) suggested that the addition of inhibitors to the $1 \mathrm{M} \mathrm{HCl}$ solution does not modify the hydrogen evolution mechanism and the reduction of $\mathrm{H}^{+}$ions at the mild steel surface which occurs mainly through a charge transfer mechanism [42].

\section{Electrochemical impedance spectroscopy measurements}

Electrochemical impedance spectroscopy is a rapid and convenient method for investigation of protective properties of organic inhibitors on metals. More reliable results can be obtained by this method, since it does not disturb the double layer at the metal/ solution interface [43]. Consequently, EIS is specially a useful method to follow the evaluation of the inhibitor-metal system over time [44].

Fig. 3 shows the Nyquist plots for carbon steel in $1 \mathrm{M} \mathrm{HCl}$ solution in the absence and presence of different concentrations of LO at $298 \mathrm{~K}$. The obtained Nyquist impedance diagrams in most cases do not show perfect semicircles, generally attributed to the frequency dispersion as a result of roughness and inhomogenates of the electrode surface. The data reveal that each impedance diagram consists of a large capacitive loop with low frequencies dispersion (inductive arc). The shape is maintained throughout the whole concentrations, indicating that almost no change in the corrosion mechanism occurred due to the inhibitor addition [45].

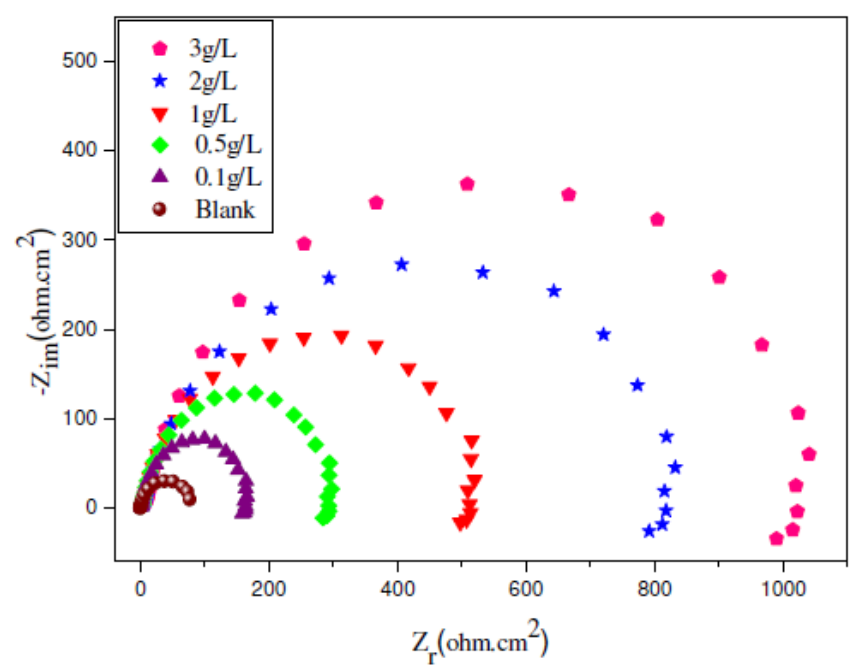

Figure 3. Nyquist diagrams for carbon steel electrode with and without $\mathrm{LO}$ at $\mathrm{E}_{\text {corr. }}$. 
In such cases, the parallel combination of double layer capacitance and charge transfer resistance which are in series with the solution resistance, particularly in the presence of an efficient inhibitor, is found to be an inadequate approach for modelling the interface. The use of the constant phase element (CPE) can be an effective way to represent the frequency dependence of non-ideal capacitive behavior, for example, corrosion of irregular and heterogeneous solid surfaces. The circuit consists of a constant phase element (CPE) Q, in parallel with a resistor $R_{t}$ The use of CPE-type impedance has been extensively described in [46-47]:

$$
\mathrm{Z}_{\mathrm{CPE}}=\left[\mathrm{Q}(\mathrm{jw})^{\mathrm{n}}\right]^{-1}
$$

The above equation provides information about the degree of non-ideality in the capacitance behavior. Its value makes it possible to differentiate between the behavior of an ideal capacitor $(n=1)$ and of a CPE $(n<1)$. Considering that a CPE may be considered as a parallel combination of a pure capacitor and a resistor that is inversely proportional to the angular frequency, the value of capacitance, $\mathrm{C}_{\mathrm{dl}}$, can thus be calculated for a parallel circuit composed of a CPE (Q) and a resistor $\left(\mathrm{R}_{\mathrm{t}}\right)$, according to the following formula [48-49]:

$$
\mathrm{Q}=\left(\mathrm{C}_{\mathrm{dl}} \mathrm{R}_{\mathrm{t}}\right)^{\mathrm{n}} / \mathrm{R}_{\mathrm{t}}
$$

The impedance spectra with one capacitive loop were analyzed by using the circuit in Fig. $4[50,51]$, and the double layer capacitance $\left(\mathrm{C}_{\mathrm{dl}}\right)$ was calculated in terms of Eq. 3.

As an example, Figs. 5 and 6 correspond to the fitted plots for EIS experiment data using the electric circuit of Fig.3 in the absence and presence of $3 \mathrm{~g} / \mathrm{L}$ of LO, respectively.

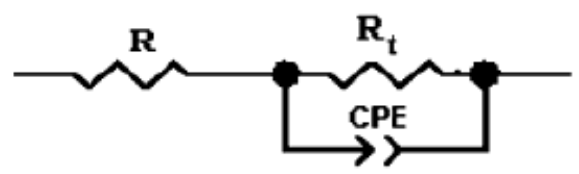

Figure 4. The equivalent circuit of the impedance spectra obtained for LO.

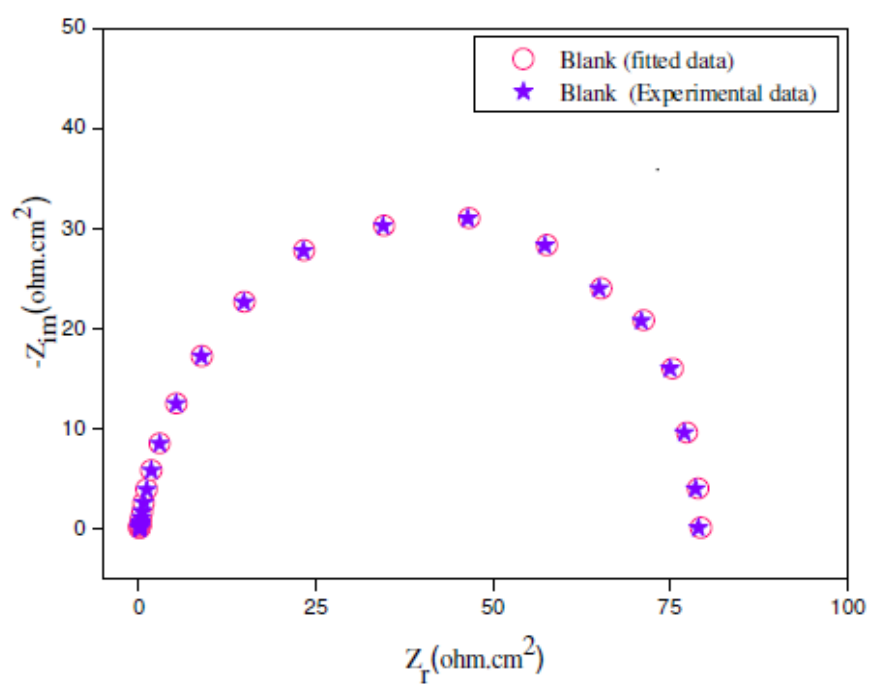

Figure 5. EIS Nyquist plots for carbon steel in $1 \mathrm{M} \mathrm{HCl}$. 


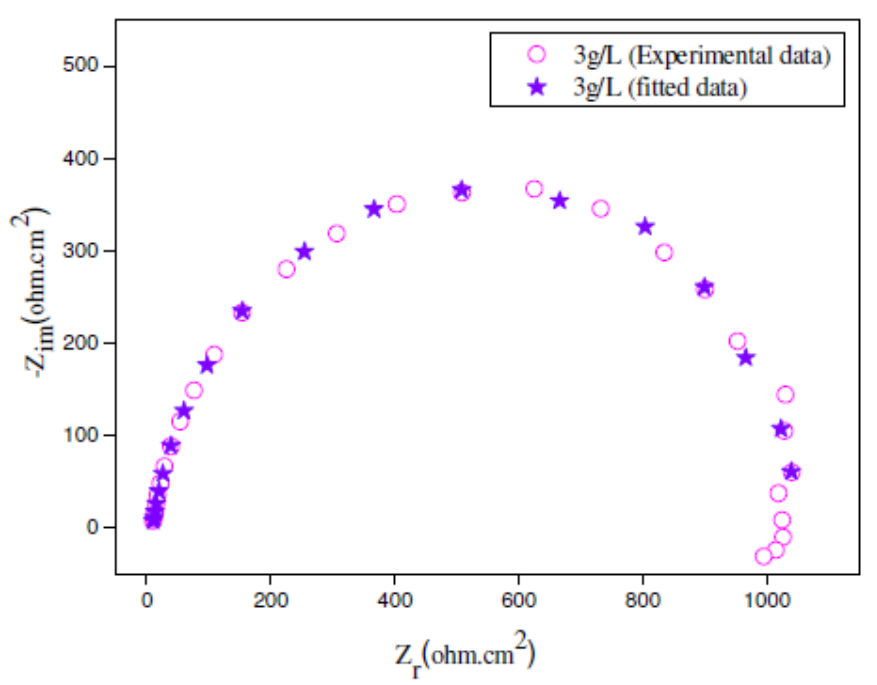

Figure 6. EIS Nyquist plots for $\mathrm{C} 38$ steel in $1 \mathrm{M} \mathrm{HCl}+3 \mathrm{~g} / \mathrm{L}$ of $\mathrm{LO}$ interface.

As it can be seen from Figs. 5 and 6, the calculated data based on the equivalent circuit given in Fig. 4 fit very well to the experimental data, and the fitted results follow the same way as the experimental ones, with an average error of about $0.01 \%$ in all the cases. This indicates that the equivalent circuit used to model the systems under investigation is the most appropriate one.

$R_{t}$ values were simultaneously determined by analysis of the complex-plane impedance plots and the equivalent circuit model and the results are very similar with insignificant changes.

The inhibition efficiency can be calculated by the following formula:

$$
E_{R t} \%=\frac{\left(R_{t}-R^{\circ}{ }_{t}\right)}{R_{t}} x 100
$$

where $R_{t}$ and $R_{t}^{0}$ are the charge transfer resistances in inhibited and uninhibited solutions, respectively.

The electrochemical impedance parameters derived from these investigations are mentioned in Table 3.

Table 3. Electrochemical impedance parameters for corrosion of steel in acid medium at various concentrations of LO.

\begin{tabular}{llllll}
\hline $\begin{array}{l}\text { Conc. } \\
(\mathbf{g} / \mathbf{L})\end{array}$ & $\begin{array}{l}\mathbf{R}_{\mathbf{t}} \\
\left(\mathbf{\Omega . c m}{ }^{2}\right)\end{array}$ & $\begin{array}{l}\mathbf{Q}^{*} \mathbf{1 0}^{-5} \\
\left(\mathbf{s}^{\mathbf{n}} \mathbf{\Omega}^{-1} \mathbf{c m}^{-2}\right)\end{array}$ & $\begin{array}{l}\mathbf{C}_{\mathbf{d l}} \\
\left(\boldsymbol{\mu F . c m} \mathbf{c m}^{-2}\right)\end{array}$ & $\mathbf{n}$ & $\begin{array}{l}\mathbf{E}_{\mathbf{R t}} \\
(\mathbf{\%})\end{array}$ \\
\hline & & & & \\
Blank & 74 & 12.82 & 75.72 & 0.8984 & --- \\
\hline 0.1 & 165 & 8.23 & 42.24 & 0.8657 & 55.2 \\
\hline 0.5 & 305 & 5.30 & 27.13 & 0.8604 & 75.7 \\
\hline 1 & 530 & 3.46 & 18.01 & 0.8598 & 86.0 \\
\hline 2 & 874 & 2.49 & 11.70 & 0.8352 & 91.5 \\
\hline 3 & 1076 & 2.13 & 9.61 & 0.8259 & 93.1 \\
\hline
\end{tabular}

The corresponding electrochemical parameters given in Table 3 reveal that the $R_{t}$ values increased as the concentration of inhibitor increased. This effect becomes 
more pronounced at higher LO concentration. This increase in the diameter of the Nyquist semicircle $\left(\mathrm{R}_{\mathrm{t}}\right.$ values), including the corresponding increase in the magnitude of the phase angle peaks in inhibited solutions, points toward improved corrosion resistance due to the corrosion-inhibiting action of LO. On the other hand, the values of double-layer capacitance $\mathrm{C}_{\mathrm{dl}}$ decreased with increasing the inhibitor concentration. This situation was the result of increasing surface coverage by the inhibitor, which led to an increase in $\mathrm{E}_{\mathrm{I}}$ to reach $93.1 \%$ at $3 \mathrm{~g} / \mathrm{L}$ of $\mathrm{LO}$.

The decrease of " $n$ " values by the increase of the inhibitor concentration can be interpreted as an evidence for steel surface adsorption of molecules [52]. The increment in polarization resistances and inhibition efficiency values and the decrease in CPE values by increasing of LO concentration may be attributed to the increase in the number of adsorbed organic molecules onto carbon steel surface $[53,54]$.

The results obtained from the polarization technique in acidic solution were in good agreement with those obtained from the electrochemical impedance spectroscopy (EIS) with a small variation.

Weight loss, corrosion rates and inhibition efficiency

The effect of the addition of LO tested at different concentrations on the corrosion of steel in $1 \mathrm{M} \mathrm{HCl}$ solution was studied by using weight-loss at $298 \mathrm{~K}$. Inhibition efficiency $\mathrm{E}_{\mathrm{w}}(\%)$ is calculated as follows:

$$
\mathrm{E}_{\mathrm{W}}(\%)=\frac{\mathrm{W}_{\text {corr }}-\mathrm{W}^{\prime} \text { corr }}{\mathrm{W}_{\text {corr }}} \times 100
$$

where $\mathrm{W}_{\text {corr }}$ and $\mathrm{W}_{\text {corr }}^{\prime}$ are the corrosion rate of carbon steel in $1 \mathrm{M} \mathrm{HCl}$ in absence and presence of the inhibitor, respectively.

Fig. 7 illustrates the variation of the corrosion rate and inhibition efficiency with concentration of inhibitor.

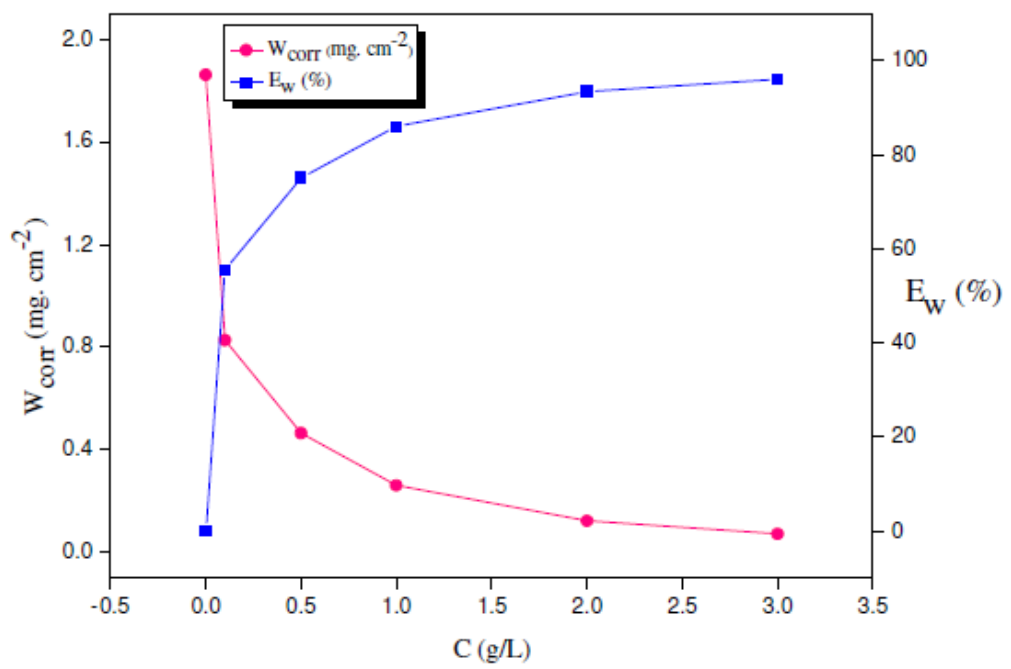

Figure 7. Variation of corrosion rate $\left(\mathrm{W}_{\text {corr }}\right)$ and inhibition efficiency $\left(\mathrm{E}_{\mathrm{W}}\right)$ with LO concentration for steel in $1 \mathrm{M} \mathrm{HCl}$ at $298 \mathrm{~K}$. 
Indeed, Fig. 7 shows that the corrosion rate values of carbon steel decrease when the inhibitor concentration increases, while $\mathrm{Ew}(\%)$ values of LO increases reaching a maximum value. This behavior can be attributed to the increase of the surface covered, $\theta$, and to the adsorption of phytochemical components of the LO onto the carbon steel surface resulting in the blocking of the reaction sites, and protecting this surface from the attack of the corrosion active ions in the acid medium. Consequently, we can conclude that LO is a good corrosion inhibitor for carbon steel in a $1 \mathrm{M} \mathrm{HCl}$ solution.

Table 4 regroups the results of weight loss of steel in $1 \mathrm{M} \mathrm{HCl}$ with and without the addition of various concentrations of the $\mathrm{LO}$.

The results in the Table 4 clearly revealed that the corrosion rate values in $1.0 \mathrm{M}$ $\mathrm{HCl}$ solution containing $\mathrm{LO}$, decreased as the concentration of the inhibitor increased. This result is due to the fact that the adsorption amount and coverage of inhibitor on steel surface increases with inhibitor concentration. The highest inhibition efficiency of $96.1 \%$ was obtained at $3 \mathrm{~g} / \mathrm{L}$ of LO. This result suggests that increase in inhibitor concentration increases the number of molecules adsorbed onto the steel surface and reduces the surface area that is available for the direct acid attack on the metal surface. The results obtained from weight loss are in good agreement with electrochemical studies.

Table 4. Effect of LO concentration on corrosion data of steel in $1 \mathrm{M} \mathrm{HCl}$.

\begin{tabular}{lll}
\hline $\begin{array}{l}\text { Conc. } \\
(\mathbf{g} / \mathbf{L})\end{array}$ & $\begin{array}{l}\mathbf{W}_{\text {corr }}^{\prime} \\
\left(\mathbf{m g . ~} \mathbf{c m}^{-2}\right)\end{array}$ & $\begin{array}{l}\mathbf{E}_{\mathbf{w}} \\
(\boldsymbol{\%})\end{array}$ \\
\hline Blank & 1.8614 & --- \\
0.1 & 0.8274 & 55.5 \\
0.5 & 0.4639 & 75.1 \\
1 & 0.2606 & 86.0 \\
2 & 0.1228 & 93.4 \\
3 & 0.0723 & 96.1 \\
\hline
\end{tabular}

\section{Effect of temperature}

Temperature has a great effect on the corrosion phenomenon. Generally, the corrosion rate increases with the rise of the temperature. For this purpose, we made potentiostatic polarization in the range of temperature 298 to $328 \mathrm{~K}$, in the absence and presence of LO at $2 \mathrm{~g} / \mathrm{L}$. The corresponding data are shown in Figs. 8,9 and Table 5.

The results obtained from polarization curves show in Figs. 8 and 9 a decrease in current density and an increase in $\mathrm{E}_{\mathrm{I}}(\%)$ with increasing temperature. Generally, the reduction of the inhibition efficiency with increasing temperature may be explained by the fact that the time lag between the process of adsorption and desorption of the inhibitor molecules over the metal surface is becoming shorter with increasing temperature [55]. Hence, the metal surface remains exposed to the acid environment for a longer period, thereby increasing the rate of corrosion with increasing temperature especially for the blank solution. The adsorption characteristics between carbon steel surface and LO molecules were not affected by rising the temperature. At higher temperatures, the calculated current density 
values of LO were lower than those of the blank solution and have decreased with temperature elevation and the inhibition efficiency values were stable even at $328 \mathrm{~K}$. The nearly constant efficiency of the inhibitors in the temperature range studied can be considered as the slight change in the nature of the adsorption mode: physisorption of the inhibitor is dominant in the temperature range studied, while chemisorption accompanied by physisorption can occur slightly with increasing the temperature. Consequently, this compound can be regarded as temperature-independent inhibitor.

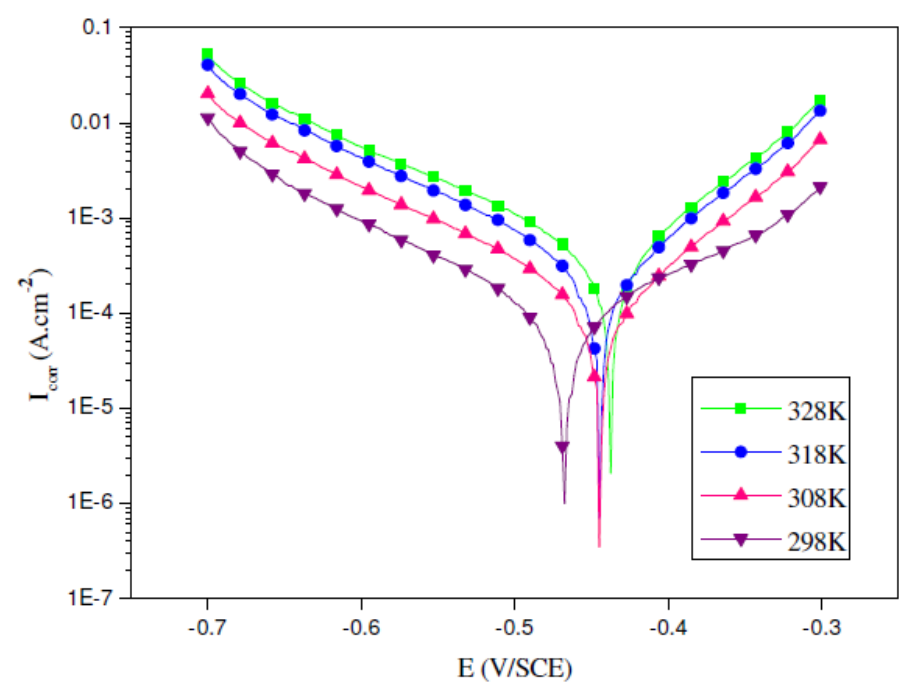

Figure 8. Polarisation curves of $\mathrm{C} 38$ steel in $1 \mathrm{M} \mathrm{HCl}$.

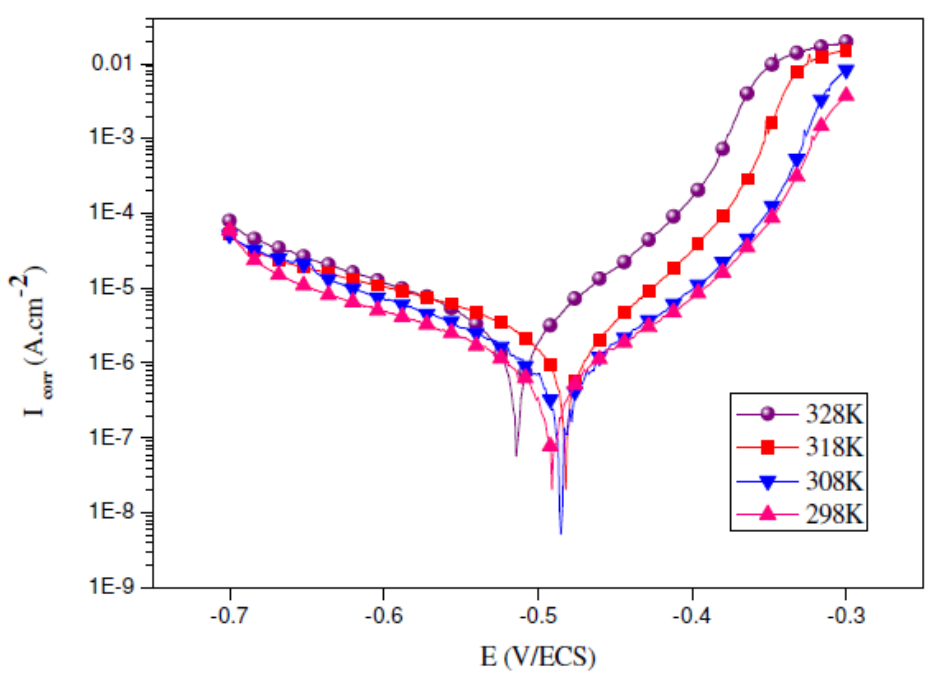

Figure 9. Polarisation curves of carbon steel in $1 \mathrm{M} \mathrm{HCl}$ in the presence of $2 \mathrm{~g} / \mathrm{L}$ of LO at different temperatures.

The activation energies of corrosion process in free and inhibited acid were calculated using Arrhenius equation:

$$
I_{\text {corr }}=A \exp \left(-\frac{E_{a}}{R \cdot T}\right)
$$


where $\mathrm{A}$ is Arrhenius factor, $\mathrm{E}_{\mathrm{a}}$ is the apparent activation corrosion energy, $\mathrm{R}$ is the perfect gas constant and $\mathrm{T}$ the absolute temperature.

Plotting $\left(\log \mathrm{I}_{\text {corr }}\right)$ versus 1/T gives straight lines, as revealed from Fig. 10.

Table 5. Effect of temperature on the steel corrosion in the absence and presence of LO at different concentrations.

\begin{tabular}{|c|c|c|c|c|c|}
\hline & $\begin{array}{l}\text { Temperature } \\
(\mathrm{K})\end{array}$ & $\begin{array}{l}\mathbf{E}_{\text {corr }} \\
(\mathrm{mV} / \mathrm{SCE})\end{array}$ & $\begin{array}{l}I_{\text {corr }} \\
(\mu \mathrm{A} / \mathrm{cm} 2)\end{array}$ & $\begin{array}{l}\text {-bc } \\
\text { (mV/dec) }\end{array}$ & $\begin{array}{l}\mathrm{E}_{\mathrm{I}} \\
(\%)\end{array}$ \\
\hline \multirow{4}{*}{ Blank } & 298 & -467 & 96 & 108 & --- \\
\hline & 308 & -444 & 157 & 126 & --- \\
\hline & 318 & -445 & 305 & 129 & --.- \\
\hline & 298 & -467 & 96 & 108 & -.-- \\
\hline \multirow[t]{4}{*}{$\mathrm{LO}$} & 298 & -489 & 4.00 & 120 & 95.8 \\
\hline & 308 & -484 & 1.77 & 128 & 98.9 \\
\hline & 318 & -484 & 4.39 & 130 & 98.6 \\
\hline & 328 & -514 & 5.55 & 131 & 98.6 \\
\hline
\end{tabular}

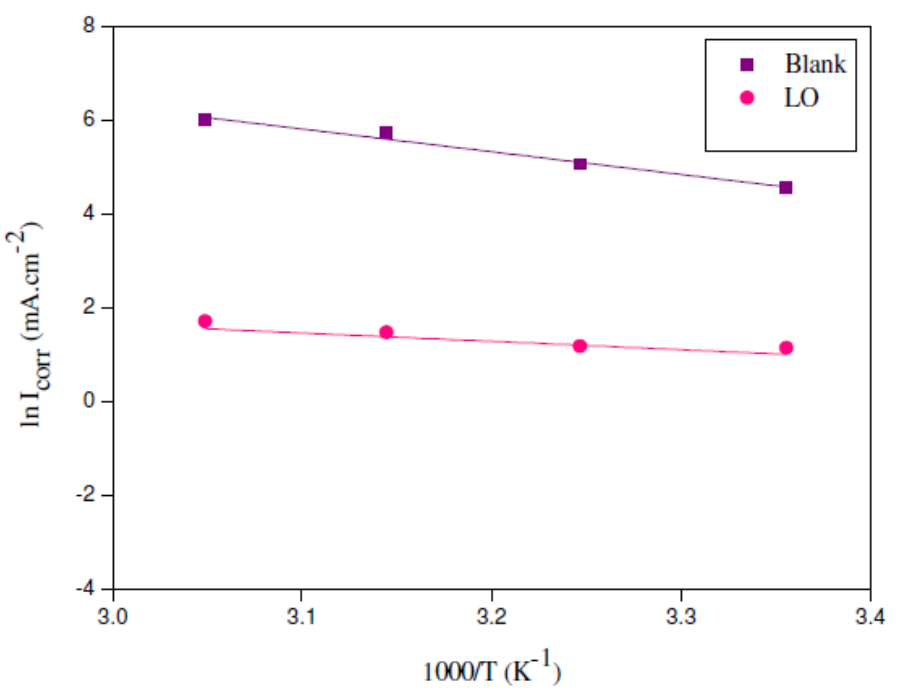

Figure 10. Arrhenius plots of steel in $1 \mathrm{M} \mathrm{HCl}$ with and without $2 \mathrm{~g} / \mathrm{L}$ of $\mathrm{LO}$.

The activation energy values obtained are 14.82 and $44.23 \mathrm{~kJ} / \mathrm{mol}$ for $2 \mathrm{~g} / \mathrm{L}$ of LO and free acid, respectively. The temperature dependence of the inhibiting effect and the comparison of the values of the apparent activation energy of the corrosion process in the absence and presence of the inhibitor can provide further evidence [56-57] concerning the mechanism of the inhibiting action. The decrease of the inhibitor efficiency with temperature rising, which refers to a higher value of $E_{a}$, when compared to that in acid media without an inhibitor, is explained as an indication for an electrostatic character of the inhibitor's adsorption. The lower value of $E_{a}$ in an inhibited solution when compared to an uninhibited one shows that chemisorption bond between the inhibitor and the metal is highly probable [58]. Activation energy, $\mathrm{E}_{\mathrm{a}}$, values in the table are very lower for inhibited solution than for the uninhibited media, indicating a high inhibitive action of the additives by increasing energy barrier for the corrosion process, emphasizing chemisorption bond between the inhibitor and the carbon steel surface (chemisorption). 
Kinetic parameters, such as enthalpy and entropy of corrosion process, may be evaluated from the effect of temperature. An alternative formulation of Arrhenius equation is (7) [59]:

$$
I_{c o r r}=\frac{R T}{N h} \cdot \exp \left(\frac{\Delta S^{*}}{R}\right) \cdot \exp \left(-\frac{\Delta H^{*}}{R T}\right)
$$

where $\mathrm{N}$ is the Avogadro's number, $\mathrm{h}$ the Plank's constant, $\mathrm{R}$ is the perfect gas constant, $\Delta \mathrm{S}^{*}$ and $\Delta \mathrm{H}^{*}$ the entropy and enthalpy of activation, respectively.

Fig. 11 shows a plot of $\ln \left(\mathrm{I}_{\text {corr }} / \mathrm{T}\right)$ against $1 / \mathrm{T}$ for LO. Straight lines are obtained with a slope of $\left(-\Delta \mathrm{H}^{*} / \mathrm{R}\right)$ and an intercept of (ln $\left.\mathrm{R} / \mathrm{Nh}+\Delta \mathrm{S} * \mathrm{R}\right)$ from which the values of $\Delta H^{*}$ and $\Delta S^{*}$, respectively, are calculated (Table 6).

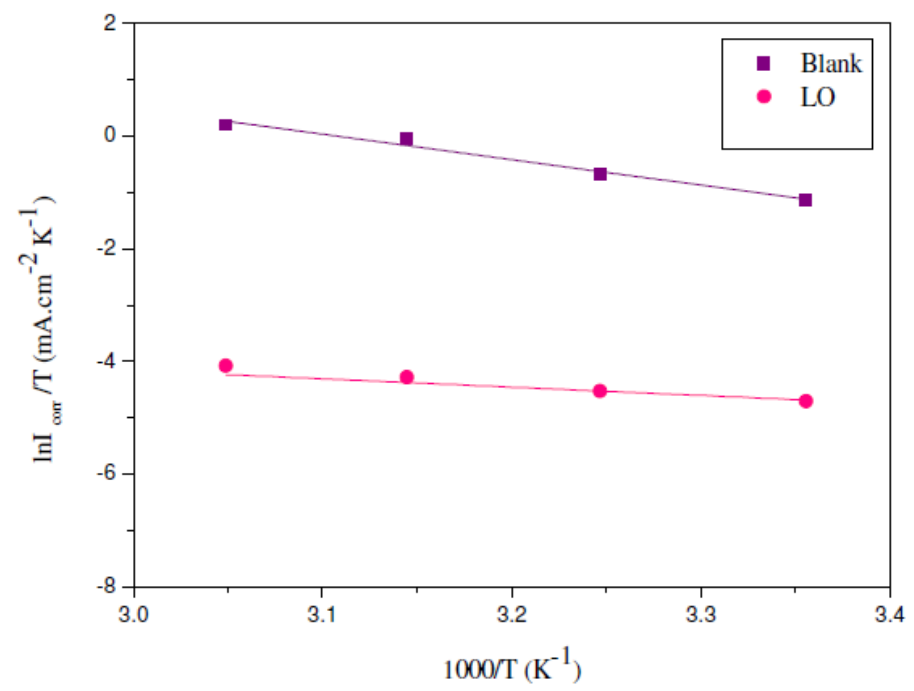

Figure 11. Relation between $\ln \left(\mathrm{W}_{\text {corr }} / \mathrm{T}\right)$ and $1000 / \mathrm{T}$ in acid at different temperatures.

Table 6. Values of the activation parameters $\Delta \mathrm{H}^{*}$ and $\Delta \mathrm{S}^{*}$ for $\mathrm{C} 38$ steel in $1 \mathrm{M} \mathrm{HCl}$ in the absence and the presence of $2 \mathrm{~g} / \mathrm{L}$ of $\mathrm{LO}$.

\begin{tabular}{llll}
\hline & $\begin{array}{l}\Delta \mathbf{H}^{*} \\
(\mathbf{k J} / \mathbf{m o l e})\end{array}$ & $\begin{array}{l}\Delta \mathbf{S}^{*} \\
\left(\mathbf{J} / \mathbf{m o l e}^{-\mathbf{1}} \cdot \mathbf{k}^{-\mathbf{1}}\right)\end{array}$ & $\mathbf{E}_{\mathbf{a}}-\Delta \mathbf{H}$ \\
\hline Blank & 41.57 & -181.88 & 2.66 \\
LO & 12.23 & -177.94 & 2.60 \\
\hline
\end{tabular}

The positive signs of $\Delta \mathrm{H}^{*}$ reflect the endothermic nature of the steel dissolution process. It is obvious that the activation energy strongly increases in the presence of the inhibitor.

The negative value of entropy $\Delta \mathrm{S}^{*}$ in the presence of the inhibitor implies that the activated complex in the rate determining step represents an association rather than a dissociation step, meaning that an increase in disordering takes place on going from reactants to the activated complex [60].

\section{Adsorption isotherm}

Basic information dealing with the interaction between the inhibitor molecules and the metal surface can be provided by the adsorption isotherm [61]. The understanding of isotherms that describe the adsorption behavior of a corrosion inhibitor is an important part of the present work, as this can provide information 
to the nature of the interaction between metal and inhibitor. In the present study several adsorption isotherms were tested and the Langmuir adsorption isotherm was found to provide best description of the adsorption behaviour of the investigated inhibitor. The Langmuir isotherm is given by the equation [62]:

$$
\begin{aligned}
& \frac{C}{\theta}=\frac{1}{\mathrm{~K}}+\mathrm{C} \\
& \mathrm{K}=\frac{1}{55.5} \exp \left(-\frac{\Delta \mathrm{G}_{\mathrm{ads}}}{\mathrm{RT}}\right)
\end{aligned}
$$

where $\mathrm{C}$ is the inhibitor concentration, $\theta$ the fraction of the surface covered determined by $\mathrm{E} / 100, \mathrm{~K}$ the equilibrium constant, $\Delta \mathrm{G}_{\mathrm{ads}}$ the standard free energy of adsorption reaction, $\mathrm{R}$ the universal gas constant, $\mathrm{T}$ the thermodynamic temperature and the value of 55.5 is the concentration of water in the solution in $\mathrm{mol} / \mathrm{L}$.

Fig. 12 shows the dependence of the ratio $\mathrm{C} / \theta$ as a function of $\mathrm{C}$.

The straight line observed on plotting $\mathrm{C} / \theta$ against $\mathrm{C}$ (Fig. 12) with a correlation coefficient higher than 0.999 suggested that the Langmuir adsorption isotherm fits best with the experimental data. The slope value being very near to unity (1.05) further confirms the validity of Langmuir adsorption isotherm.

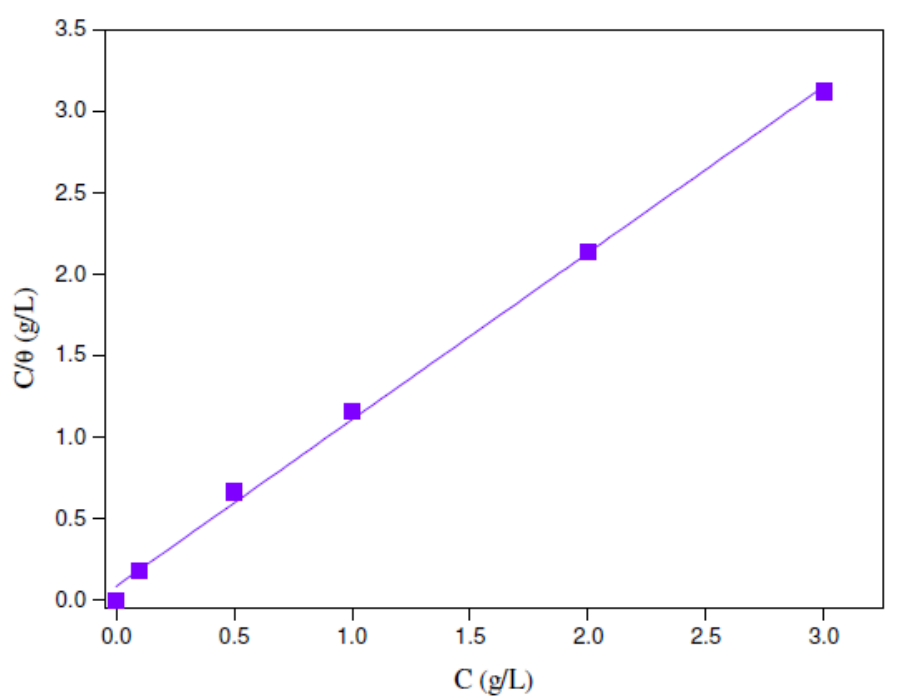

Figure 12. Plots of Langmuir adsorption isotherm of LO on the steel surface at $298 \mathrm{~K}$.

\section{Conclusions}

The following results can be drawn from this study:

- The major constituents of linseed oil were linolenic, oleic and linoleic acid.

- Linseed oil acts as an excellent mixed inhibitor without modifying the hydrogen reduction mechanism.

- The inhibition efficiency increases with increased LO concentration to attain a maximum value of $98.8 \%$ at $3 \mathrm{~g} / \mathrm{L}$.

- The LO provides good inhibition of the corrosion of carbon steel in normal hydrochloric acid medium. 
- The data obtained from the three different methods (potentiodynamic polarisation, EIS and weight loss) are in good agreement.

- The inhibition efficiency of LO is independent of the temperature.

- Langmuir adsorption isotherm exhibited the best fit to the experimental data.

\section{References}

1. Oguzie EE. Corros Sci. 2008;50:2993.

2. Bentrah H, Rahali Y, Chala A. Corros Sci. 2014;82:426.

3. Ostovari A, Hoseinieh SM, Peikari M, et al. Corros Sci. 2009;51:1935.

4. Torres VV, Amado RS, Sá CF, et al. Corros Sci. 2011;53:2385.

5. Banerjee S, Srivastava V, Singh MM. Corros Sci. 2012;59:35.

6. Hosseini MG, Ehteshamzadeh M, Shahrabi T. Electrochim Acta. 2007;52:3680.

7. Fan HB, Fu CY, Wang HL, et al. Br Corros J. 2002;37:122.

8. Afia L, Salghi R, Zarrouk A, et al. Trans Indian Inst Met. 2013;66:43.

9. Afia L, Salghi R, Zarrouk A, et al. Port Electrochim Acta. 2012;30:267.

10. Afia L, Salghi R, Bazzi El, et al. Res Chem Intermed.2012;38:1707.

11. Afia L, Salghi R, Bammou L, et al. Acta Metall Sin. 2012;25:10.

12. Afia L, Salghi R, Bammou L, et al. J Saudi Chem Soc. 2014:18.

13. Afia L, Salghi R, Bazzi El, et al. Int J Electrochem Sci. 2011;6:5918.

14. Gerengi H, Sahin HI. Ind Eng Chem Res. 2012;51:780.

15. Lebrini M, Robert F, Lecante A, et al. Corros Sci. 2011;53:687.

16. Gopalji SK, Shukla P, Dwivedi S, et al. Ind Eng Chem Res. 2011;50:11954.

17. Raja PB, Qureshi AK, Rahim AA, et al. Corros Sci. 2013;69:292.

18. Satapathy AK, Gunasekaran G, Sahoo SC, et al. Corros Sci. 2009;51:2848.

19. Abiola OK, James AO, Corros Sci. 2010;52:661.

20. Singh MM. Corros Sci. 2014;85:352.

21. Asipita SA, Ismail M, Muhd Zaimi AM, et al. J Clean Product. 2014;67:139.

22. Golestani Gh, Shahidi M, Ghazanfari D. Appl Surf Sci. 2014;308:347.

23. Shuduan D, Xianghong L. Corros Sci. 2012;64:253.

24. Negm NA, Zaki MF, Said MM, et al. Corros Sci. 2011;53:4233.

25. Bentrah H, Rahali Y, Chala A. Corros Sci. 2014;82:426.

26. Banerjee S, Srivastava V, Singh MM. Corros Sci. 2012;59:35.

27. Ramananda SM. J Mater Environ Sci. 2013;4:117.

28. Vijayakumari B, Sasikala V, Radha SR, et al. Pharmace Sci. 2013;2:6371.

29. Akalezi CO, Enenebaku CK, Oguzie EE. J Mater Environ Sci. 2013;4:217.

30. Benali O, Benmehdi H, Hasnaoui O, et al. J Mater Environ Sci. 2013;4:127.

31. Bligh EG, Dyer WJ. Can J Biochem Physio. 1959;137:911.

32. DGF, Deutsche Einheitsmethoden zur Untersuchung von Fetten, Fettprodukten, Tensiden und verwandten Stoffen. Stuttgart: Wissenschaftliche Verlagsgesellschaft; 2008.

33. Balz M, Schulte E, Thier HP. Sci Technology. 1992;94:209.

34. Li XH, Deng SD, Fu H. Corros Sci. 2009;51:1344. 
35. Ferreira ES, Giancomelli C, Giacomelli FC, et al. Mater Chem Phys. 2004;83:129.

36. Li X, Deng S, Fu H. Corros Sci. 2011;53:302.

37. Lagrenee M, Mernari B, Bouanis M, et al. Corros Sci. 2002;44:573.

38. Ferreira ES, Giancomelli C, Giacomelli FC, et al. Mater Chem Phys. 2004;83:129.

39. Behpour M, Ghoreishi SM, Khayatkashani M, et al. Corros Sci. 2011;53:2489.

40. Okafor PC, Zheng Y. Corros Sci. 2009;51:850.

41. Ahamad I, Prasad R. Corros Sci. 2010;52:933.

42. Fuchs-Godec R. Electrochim Acta 2007;52:4974.

43. Elayyachy M, Elkodadi M, Aouniti A, et al. Mater Chem Phys. 2005;93:281.

44. Bayol E, Kayakırılmaz K, Erbil M. Mater Chem Phys. 2007;104:74.

45. Erbil M. Chim Acta Turc. 1988;1:59.

46. Solmaz R, Kardas G, Yazicı B, et al. Colloids Surf A. 2008;312:7.

47. Merah S, Larabi L, Benali O, et al. Pig Res Tech. 2008;37:291.

48. Ma H, Chen S, Yin B, et al. Corros Sci. 2003;45:867.

49. McCafferty E. Corros Sci. 1997;39:243.

50. Morad MS. Corros Sci. 2000;42:1313.

51. Amin MA, Khaled KF. Corros Sci. 2010;52:1194.

52. Surme Y, Gurten AA, Bayol E. Prot Met Phys Chem. 2011;47:117.

53. Bayol E, Gurten T, Gurten AA, et al. Chem Phys. 2008;112:624.

54. Noor EA, Al-Moubaraki AH. Mater Chem Phys. 2008;110:145.

55. Bensajjay E, Alehyen S, El Achouri M, et al. Anti-Corros Meth Mater. 2003;50:402.

56. Ivanov ES. Inhibitors for Metal Corrosion in Acid Media. Moscow:Metallurgy; 1986.

57. Zerga B, Attayibat A, Sfaira M, et al. J Appl Electrochem. 2010;40:1575.

58. Abd-El-Rehim SS, Refaey SAM, Taha F, et al. J Appl Electrochem. 2001;31:429.

59. Guan NM, Xueming L, Fei L. Mater Chem Phys. 2004;86:59.

60. Noor EA, Al-Moubaraki AH. Mater Chem Phys. 2008;110:145.

61. Bouklah M, Hammouti B, Lagrenee M, et al. Corros Sci. 2006;48:2831.

62. Langmuir I. J Am Chem Soc. 1947;39:1848. 